\title{
Lymphadenitis in children is caused by Mycobacterium avium hominissuis and not related to 'bird tuberculosis'
}

\author{
L. E. S. Bruijnesteijn van Coppenraet • \\ P. E. W. de Haas • J. A. Lindeboom • E. J. Kuijper • \\ D. van Soolingen
}

Received: 30 July 2007 / Accepted: 23 November 2007 /Published online: 5 March 2008

(C) The Author(s) 2007

\begin{abstract}
Mycobacterium avium is the most commonly encountered mycobacterium species among nonMycobacterium tuberculosis complex (nontuberculous mycobacteria) isolates worldwide and frequently causes lymphadenitis in children. During a multi-centre study in The Netherlands that was performed to determine the optimal treatment for mycobacterial lymphadenitis, concern was expressed in the media about the possible role of birds as sources of these $M$. avium infections, referred to as 'bird tuberculosis.' To examine the involvement of birds in mycobacterial lymphadenitis, $34 \mathrm{M}$. avium isolates from lymphadenitis cases were subjected to IS1245 restriction fragment length polymorphism (RFLP) typing. This genotyping method enables the distinction of the subspecies M. avium subsp. hominissuis and the 'bird-type' $M$. avium spp. avium. Highly variable RFLP patterns were found among the lymphadenitis $M$. avium isolates, and all belonged to the $M$. avium hominissuis subspecies. A relation to pet birds in the etiology of mycobacterial lymphadenitis could
\end{abstract}

L. E. S. Bruijnesteijn van Coppenraet $(\bowtie) \cdot$ E. J. Kuijper Department of Medical Microbiology,

Center of Infectious Diseases, Leiden University Medical Center,

Leiden, The Netherlands

e-mail: e.s.bruijnesteijn@isala.nl

P. E. W. de Haas · D. van Soolingen

Mycobacterial Reference Laboratory,

National Institute for Public Health and the Environment,

Bilthoven, The Netherlands

J. A. Lindeboom

Department of Oral and Maxillofacial Surgery,

Academic Medical Center,

Amsterdam, The Netherlands not be established, and the source of the infections may be environmental.

\section{Introduction}

While the absolute number of clinical isolates of nontuberculous mycobacteria (NTM) has worldwide increased gradually with the upcoming of the acquired immunodeficiency syndrome (AIDS), the number of isolates in The Netherlands remained stable in the last decade. In the period from 1996 to 2005, 4,640 NTM isolates were collected at the national tuberculosis reference laboratory (Dutch National Institute for Public Health and the Environment, RIVM), of which 1,484 (32\%) belonged to the M. avium complex. Mycobacterium avium is not only a well-known cause of pulmonary disease, especially in immunocompromised patients, but is also the most commonly encountered species in mycobacterial lymphadenitis in children. The exact incidence of $M$. avium lymphadenitis is difficult to assess but is estimated at 1.15 per 100,000 children (1-18 years) in The Netherlands [1].

From 2001 to 2004, a nationwide multi-centre study to examine the optimal treatment of NTM mycobacterial cervicofacial lymphadenitis (surgery vs medical therapy) was performed [2]. In this study, it was found that 94 (70\%) of 135 diagnosed Mycobacterium infections were caused by M. avium [3]. As a consequence of this study, numerous articles appeared in regional and national newspapers in The Netherlands in which the concern was expressed that mycobacterial lymphadenitis in children is a form of 'bird tuberculosis' (selection of newspaper articles: [4-8]). This is based on the conventional but still widely accepted dogma that $M$. avium infections in humans are derived from birds. Moreover, many patients included in the 
treatment study and diagnosed with $M$. avium-associated lymphadenitis appeared to keep pet birds in the household or had an otherwise frequent contact with birds, as was demonstrated in a questionnaire for epidemiological purposes [3]. However, no demographic information on the presence of pet birds in the general population in The Netherlands is available, and it therefore remains unclear whether there is any correlation between household pets and lymphadenitis in children.

With the improved possibilities for the diagnosis of mycobacterial infections, new (sub-)species have been identified, and new insights in taxonomy are being developed. Previously, in the M. avium-M. intracellulare complex, 28 serotypes were distinguished [9]. The species M. avium consists of the subspecies $M$. avium ssp. avium, M. avium ssp. silvaticum and M. avium ssp. paratuberculosis [10]. Restriction fragment length polymorphism (RFLP) typing, using insertion sequence IS1245 as a probe, is a standardised epidemiological tool for the molecular typing of $M$. avium $[11,12]$. The targeted insertion element IS1245 is specific for the species M. avium and is present in a highly variable number and location in the genome of these bacteria.

Application of this typing method led to the recognition that M. avium isolates from birds of a wide variety of species exhibited one identical pattern [12-15]. This three band pattern was designated the 'bird-type' RFLP pattern. To exclude the raised confusion in the epidemiology of M. avium infections, the 'bird-type' $M$. avium strains were further characterised, and this subspecies was named M. avium avium [14]. The $M$. avium isolates from human and porcine sources showed highly polymorphic IS1245 RFLP patterns and were designated ' $M$. avium hominissuis' [14].

In this study, the contribution of the bird-type M. avium avium to lymphadenitis in children in The Netherlands is examined to confirm or exclude the involvement of birds in the aetiology of this disease.

\section{Materials and methods}

Strains and culturing methods

M. avium strains were isolated from children included in the lymphadenitis treatment study. Inclusion criteria for this study were an enlarged cervicofacial lymphadenitis for a period longer than 3 weeks, with negative serology for other infectious causes of chronic lymphadenitis. Excluded were patients with an immunosuppressive therapy or disease [3]. In addition, skin testing with $M$. tuberculosis complex and three NTM sensitins was performed [16]. Diagnosis was confirmed by culture and/or specific real-time polymerase chain reaction (PCR), performed on lymph node aspirates or surgically obtained tissue biopsies [3, 17]. Culturing was performed at $35^{\circ} \mathrm{C}$ in liquid Mycobacteria growth indicator tube medium enriched with polymyxin B-amphotericin Bnalidixic acid-trimethoprim-azlocillin mixture and oleic acid-albumin-dextrose complex or on solid Löwenstein Jensen medium (Becton Dickinson, Alphen a/d Rijn, The Netherlands). Strains were sent to the RIVM in Bilthoven and processed in IS1245 RFLP typing (Table 1).

\section{Species identification}

Real-time PCR was performed as described previously [17]. A genus-specific and a $M$. avium-specific PCR were performed on all isolated strains as well as on deoxyribonucleic acid (DNA) extracts of bird materials. When a positive signal was found in exclusively the genus-specific real-time PCR, the amplicon was purified using a gel-extraction kit (Qiagen, Venlo, The Netherlands), and the PCR product was sequenced to determine the species the respective bacteria belonged to. Sequencing was performed on basis of the PCR primers using the Big Dye Terminator ready reaction mix (Applied Biosystems, Nieuwerkerk a/d IJssel, The Netherlands) and analysed on an ABI 3100 automatic Sequencer (Applied Biosystems). A second identification was performed at the RIVM, either by $16 \mathrm{~S}$ sequencing [18] or by a reverse line blot (InnoLipa V2, Innogenetics, Gent, Belgium), to confirm the identity of the M. avium strains.

\section{Molecular typing}

A database has previously been assembled by the RIVM of RFLP patterns from M. avium isolates from humans in The Netherlands in the period 1996-1997 or from animals and soil in a period of decades. IS1245 RFLP typing was performed as described previously [11, 15]. RFLP patterns of $34 \mathrm{M}$. avium isolates from lymphadenitis cases were analysed and compared with known patterns in the database using the Bionumerics software (Applied Maths BVBA, Sint-Martens-Latem, Belgium).

\section{Bird materials}

Materials of pet birds from two patients diagnosed with M. avium-associated lymphadenitis were collected. One patient owned two parakeets and kept them inside the house. Another owned eight parakeets, and they were kept in an aviary in the yard. Considering the age of the included children, it is not expected that the children were the direct caretakers of the birds. The parakeets had different ages, gender and breed. The birds did not show any sign of illness. Swabs were collected from the cloacae of the parakeets, and faeces were scraped from the bottom of the cages (as fresh as possible). All samples were divided equally in two portions and examined by two different institutes (National Institute 
Table 1 Characteristics of patient strains

\begin{tabular}{|c|c|c|c|c|c|c|c|c|c|c|}
\hline Strain number & $\begin{array}{l}\text { Onset of } \\
\text { disease }\end{array}$ & $\begin{array}{l}\text { County/ } \\
\text { region }\end{array}$ & $\begin{array}{l}\text { Age } \\
\text { (month) }\end{array}$ & Pets & Swimming & Sandpit & $\begin{array}{l}\text { Children's } \\
\text { farm }\end{array}$ & Season & $\begin{array}{l}\text { Ethnic } \\
\text { background }\end{array}$ & $\begin{array}{l}\text { Typing } \\
\text { details }^{\mathrm{a}}\end{array}$ \\
\hline NLA000102014 & June 2001 & FL & 35 & - & - & + & + & Summer & $\mathrm{NE}$ & \\
\hline NLA000200875 & Feb 2002 & OI & 20 & + & - & - & - & Spring & $\mathrm{NE}$ & \\
\hline NLA000201583 & June 2002 & $\mathrm{NH}$ & 25 & - & - & + & + & Summer & $\mathrm{NE}$ & \\
\hline NLA000201584 & July 2002 & $\mathrm{NH}$ & 19 & - & - & - & - & Summer & $\mathrm{NE}$ & \\
\hline NLA000201871 & July 2002 & $\mathrm{NH}$ & 21 & - & - & - & - & Autumn & $\mathrm{NE}$ & \\
\hline NLA000300211 & Sept 2002 & GL & 27 & - & - & + & + & Autumn & $\mathrm{NE}$ & \\
\hline NLA000300212 & Oct 2002 & FL & 34 & - & - & + & - & Autumn & Afghanistan & $\begin{array}{l}\text { Clade } \\
7502\end{array}$ \\
\hline NLA000300987 & Oct 2002 & $\mathrm{ZH}$ & 148 & + & + & - & - & Winter & $\mathrm{NE}$ & $\beta$ \\
\hline NLA000300601 & Jan 2003 & FL & 38 & + & - & + & + & Winter & $\mathrm{NE}$ & $\begin{array}{l}\text { Clade } \\
7509\end{array}$ \\
\hline NLA000400124 & May 2003 & $\mathrm{ZH}$ & 31 & + & - & - & - & Winter & $\mathrm{NE}$ & $\delta$ \\
\hline NLA000300985 & Feb 2003 & GL & 67 & + & + & - & - & Spring & $\mathrm{NE}$ & $\beta$ \\
\hline NLA000300986 & Feb 2003 & $\mathrm{NH}$ & 18 & + & - & - & - & Winter & $\mathrm{NE}$ & $\begin{array}{l}\text { Clade } \\
7501\end{array}$ \\
\hline NLA000302015 & July 2003 & $\mathrm{NH}$ & 45 & - & - & + & - & Summer & $\mathrm{NE}$ & \\
\hline NLA000301141 & Mar 2003 & LB & 57 & + & + & + & - & Spring & $\mathrm{NE}$ & $\begin{array}{l}\text { Clade } \\
7509\end{array}$ \\
\hline NLA000301142 & Mar 2003 & Dr & 17 & + & - & + & + & Spring & NE & $\begin{array}{l}\text { Clade } \\
7501\end{array}$ \\
\hline NLA000302014 & July 2003 & NB & 15 & + & - & - & - & Spring & $\mathrm{NE}$ & $\begin{array}{l}\text { Clade } \\
7509\end{array}$ \\
\hline NLA000302016 & May 2003 & $\mathrm{NH}$ & 50 & - & + & + & + & Spring & $\mathrm{NE}$ & $\gamma$ \\
\hline NLA000302013 & June 2003 & FL & 73 & - & + & - & + & Summer & $\begin{array}{c}\text { Morocco } \\
\text { (half) }\end{array}$ & $\gamma$ \\
\hline NLA000400892 & May 2003 & NB & 47 & + & + & + & - & Autumn & $\mathrm{NE}$ & $\alpha$ \\
\hline NLA000302203 & July 2003 & NB & 21 & - & - & - & - & Autumn & $\mathrm{NE}$ & $\begin{array}{l}\text { Clade } \\
7509\end{array}$ \\
\hline NLA000302205 & Sept 2003 & ZL & 58 & + & + & + & - & Autumn & $\mathrm{NE}$ & $\delta$ \\
\hline NLA000302204 & May 2003 & $\mathrm{ZL}$ & 36 & + & + & + & - & Spring & $\mathrm{NE}$ & $\begin{array}{l}\text { Clade } \\
7502\end{array}$ \\
\hline NLA000302300 & Aug 2003 & UR & 25 & + & - & + & - & Autumn & $\mathrm{NE}$ & \\
\hline NLA000400059 & Sept 2003 & GL & 47 & - & - & + & + & Autumn & $\mathrm{NE}$ & $\begin{array}{l}\text { Clade } \\
7502\end{array}$ \\
\hline NLA000400274 & Dec 2003 & GL & 20 & - & - & + & - & Winter & $\mathrm{NE}$ & $\begin{array}{l}\text { Clade } \\
7501\end{array}$ \\
\hline NLA000400819 & Feb 2004 & NB & 104 & + & + & - & - & Autumn & $\mathrm{NE}$ & $\begin{array}{l}\text { Clade } \\
7502\end{array}$ \\
\hline NLA000400398 & Nov 2003 & $\mathrm{ZH}$ & 44 & - & + & + & + & Autumn & $\mathrm{NE}$ & $\begin{array}{l}\text { Clade } \\
7502\end{array}$ \\
\hline NLA000400620 & Dec 2003 & NH & 27 & + & - & + & - & Winter & $\mathrm{NE}$ & $\begin{array}{l}\text { Clade } \\
7501\end{array}$ \\
\hline NLA000400619 & Feb 2004 & $\mathrm{NH}$ & 26 & - & - & - & - & Winter & $\mathrm{NE}$ & \\
\hline NLA000400821 & Feb 2004 & $\mathrm{NH}$ & 52 & + & + & + & + & Winter & NE & $\alpha$ \\
\hline NLA000400895 & Mar 2004 & $\mathrm{NH}$ & 18 & - & - & - & - & Spring & $\mathrm{NE}$ & \\
\hline NLA000401217 & Feb 2004 & NB & 56 & - & + & + & - & Spring & $\mathrm{NE}$ & Clade II/ع \\
\hline NLA000401218 & Feb 2004 & LB & 19 & + & - & + & - & Spring & NE & Clade I \\
\hline NLA000300854 & Feb 2004 & FL & 32 & + & + & + & + & Spring & $\mathrm{NE}$ & Clade II/ع \\
\hline
\end{tabular}

${ }^{\text {a }}$ Typing details include clade designation according to Komijn et al. [19] and similarity (95-100\%) designation between strains of this collection: $\alpha, \beta, \gamma, \delta$ or $\varepsilon$ 
for Animal Disease Control Lelystad, and Leiden University Medical Center, Leiden, The Netherlands). Swabs were processed as clinical materials [17] and decontaminated once with the Nalc-NaOH method before culture. Faeces were decontaminated twice before culture but otherwise processed identically, including the culturing. One institute also performed real-time PCR for the direct detection of mycobacterial DNA in the bird materials.

\section{Results}

Human materials

In the lymphadenitis treatment study, 210 lymph node biopsies of cervicofacial lymphadenitis patients were examined for the presence of mycobacteria by culture and real-time PCR [2, 17]. Mycobacterial infection was diagnosed in 138 children, of which 94 (70\%) were caused by $M$. avium. Sixty positive cultures were obtained in the 4 years period of the study. All positive $M$. avium cultures between November 2001 and June $2004(n=34)$ were sent to the RIVM and subjected to RFLP typing.

Analysis of the background information of the 34 children demonstrated only one child to have ducks in the immediate vicinity of its house, and none of the 34 children had been into direct contact with horses, chickens, geese, pigs, goats and pigeons. Twenty-one (62\%) children, however, played in a sandpit, $13(38 \%)$ children swam in a closed swimming pool (none in open water) and a total of $18(53 \%)$ children had pet animals of which in $33 \%$ of the cases, this concerned birds (Table 1).

\section{Molecular typing}

In total, $34 \mathrm{M}$. avium isolates from the patients included in the lymphadenitis treatment study were subjected to IS 1245 RFLP typing, and the results are depicted in Fig. 1. Among the M. avium isolates of the lymphadenitis patients, a high variety of multi-banded IS1245 RFLP types was found, and all belonged to the subspecies avium hominissuis and not to M. avium ssp. avium. The obtained IS1245 RFLP patterns were compared with the Dutch IS1245 RFLP database and showed similarity with the patterns of previously described genotype families in The Netherlands (clades 7501-7509) [19]. No association was found between the clades - to which the isolates were assigned to - and pet birds or other pet animals, time of onset of the disease, playing in sandpits, visiting the children's farm, swimming or location of housing.

In addition, no geographical clustering could be found for these strains; the residence of the respective patients appeared to be completely random in The Netherlands. In fact, the RFLP patterns of several M. avium strains were $95-100 \%$ similar to that of another strain while no correlation was observed with any patient factor (Table 1: designation $\alpha-\varepsilon$ ).

Bird materials

Culture and real-time PCR performed on the bird materials revealed two faeces specimens positive for mycobacteria. One was only detected by culture and was identified as M. terrae. The other one was concordantly detected by culture and real-time PCR and identified as M. malmoense. Both identifications were done by sequencing the internal transcribed spacer region and by comparison in the National Center for Biotechnology Information database (http://www.ncbi.nlm.nih.gov).

\section{Discussion}

Atypical mycobacteria are ubiquitously present in our environment, but few clinical cases have so far been directly linked to their natural reservoirs [20-22]. Traditionally, lymphadenitis in children caused by M. avium is indicated as 'bird tuberculosis' because historically M. avium bacteria were thought to have an association with birds. Because a striking percentage of the lymphadenitis patients in The Netherlands were in contact with birds, the concern was expressed in the media that birds were the source of infection for these lymphadenitis cases. This was not only driven by the fact that children naturally play outside in sand and soil but also by the fact that 8 of 34 children were in households where pet birds were present. Therefore, in this study, M. avium isolates from the lymph nodes of 34 children with lymphadenitis were subjected to IS 1245 RFLP typing and compared. The main objective in this comparison was to verify the occurrence of the bird-type $M$. avium within this group of patients. Although the patient strains revealed a high degree of variation in the IS1245 RFLP patterns, the bird-type was not found in any of the 34 $M$. avium isolates, which excludes the possibility that birdtype strains are the source of infection. Moreover, no M. avium could be isolated from bird materials collected from the patients' pet birds.

In several studies, this DNA typing method has been applied for epidemiological purposes [12, 13, 19, 23-25], and almost all $M$. avium isolates from birds revealed a characteristic bird-type three-banded IS1245 RFLP pattern, while multi-banded RFLP types were very rarely encountered in bird isolates. The method has been investigated for its stability of patterns [26], and its specificity for the IS 1245 has been discussed in several papers $[12,27]$.

Earlier studies (partially published: [19]) conducted by the RIVM demonstrated a high degree of similarity 


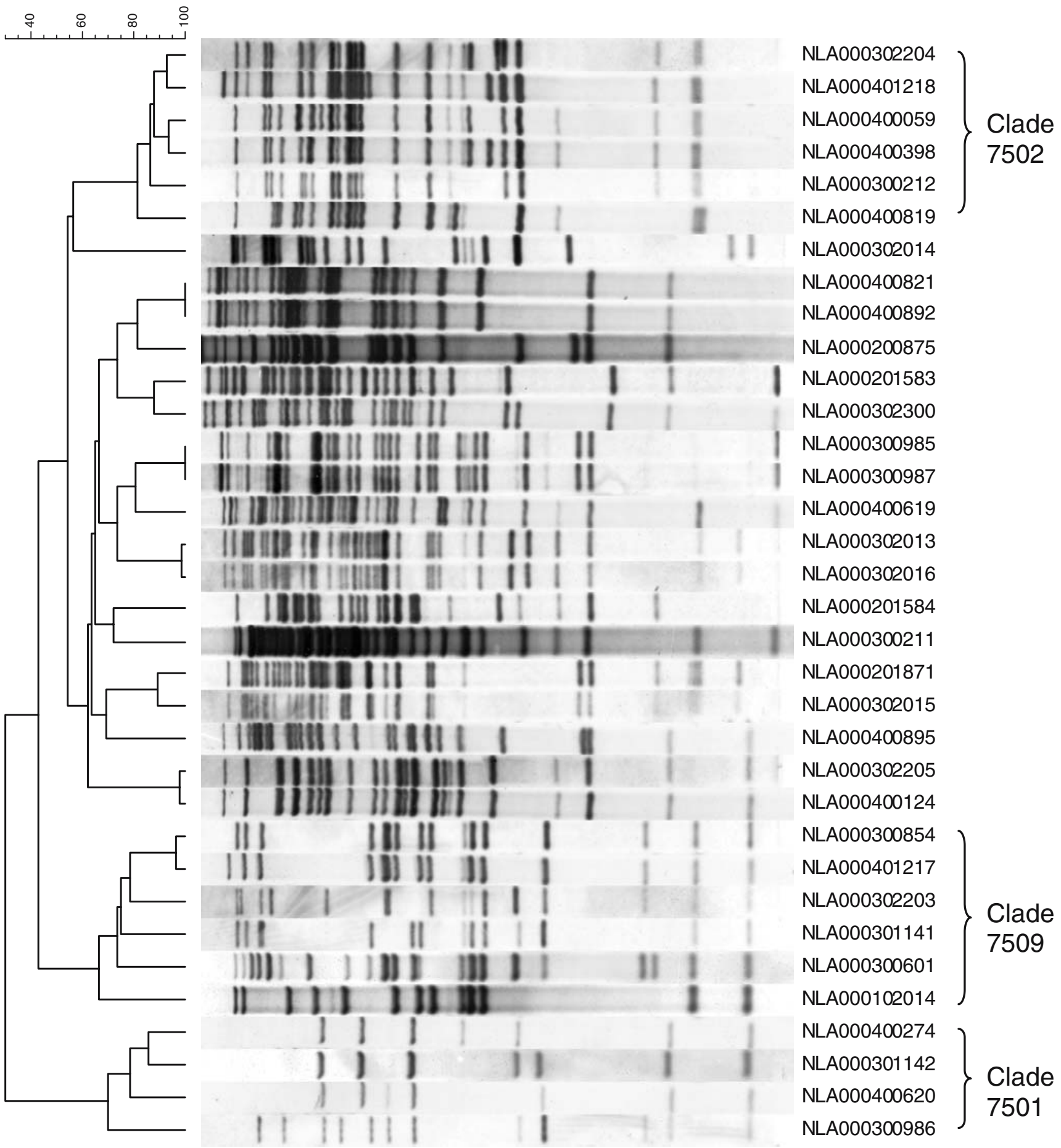

Fig. 1 Comparison of IS1245 RFLP patterns of all M. avium strains. Analysis in Bionumerics. Clade designation according to Komijn et al. [19]

between human and porcine $M$. avium isolates. IS 1245 RFLP typing of 146 isolates from humans in The Netherlands - the total number of $M$. avium strains collected in the year 1996 and 1997-yielded highly variable DNA fingerprint patterns, and a large part of the isolates could be assigned to nine different clades with a high degree of similarity among the RFLP patterns. A large part of the isolates both from human and porcine sources were grouped in the same clades.

The M. avium isolates of this study were scattered over several clades as was similarly found for the lymphadenitis isolates from the period 1996 to 1997. Six strains from this 
study belonged to clade 7502 in which in previous studies the majority of strains from human immunodeficiency virusinfected patients clustered (unpublished thesis, Schneider, Bilthoven, The Netherlands). The high variability among the RFLP patterns may demonstrate the presence of high numbers of $M$. avium hominissuis bacteria in environmental sources and/or variability in source of infection.

While a high degree of variation was generally observed between the typed $M$. avium strains of the lymphadenitis cases, several patient strains were identical to one other strain. Comparison of the strains to the IS1245 RFLP database showed one strain from 1996 to be identical to one strain from 2004. This indicates the long-term genomic stability of the representative strains and the ability of these bacteria to prevail in a stable niche.

The bird-type $M$. avium has been isolated from birds [12, 28] and proven to be virulent in birds [29]. The birds kept in the patients' home showed no detectable signs of illness. However, while mycobacteriosis is cause of mortality in birds, infected birds often show no signs of previous disease [30]. Pet birds might be carriers of $M$. avium subsp. hominissuis strains and could therefore transmit these M. avium bacteria to children causing lymphadenitis in a significant number of them. While mycobacteriosis in birds can best be diagnosed using biopsies from liver or spleen [31], successful isolation of mycobacteria has been described from faeces and cloacal swabs [31,32] from infected birds. In this study, however, we were not able to grow $M$. avium from bird faeces and cloaca swabs. Therefore, this hypothetical carriership of birds could not be confirmed. Because the pilot experiment with bird materials was very small in size and the materials were not collected at time of onset of the disease, the possibility that pet birds are carriers of $M$. avium hominissuis cannot be completely excluded. The pet birds can also be an indirect cause; because M. avium is ubiquitous in soil, water, animals, food and sawdust [19, 20, 24, 33], these bacteria may well spread directly from such sources.

No other contact with farm animals than an occasional trip to the children's farm (33\%) was apparent in these patients as shown in Table 1. Therefore, pigs or other farm animals are not likely to have served as sources of infection [24].

Reed et al. [34] described in a random household survey conducted in Florida that the only apparent risk factor for $M$. avium infection is prolonged exposure to soil. Von Reyn et al. [35] described that while some clinical M. avium cases in AIDS patients could be linked to the household water supply by molecular typing, colonisation of the water supply with $M$. avium does not increase the risk of infection.

No correlation could be found in strain distribution with any kind of behaviour or geographical residence of the patient [3]. We therefore conclude that the sources of $M$. avium causing lymphadenitis in The Netherlands are variable and ubiquitous and no relation to pet birds has been determined.
Acknowledgement We gratefully acknowledge the National Institute for Animal Disease Control (CIDC) Lelystadt, The Netherlands, for advice on sampling bird materials and performing mycobacterial cultures from bird materials.

Open Access This article is distributed under the terms of the Creative Commons Attribution Noncommercial License which permits any noncommercial use, distribution, and reproduction in any medium, provided the original author(s) and source are credited.

\section{References}

1. Haverkamp MH, Arend SM, Lindeboom JA, Hartwig NG, van Dissel JT (2004) Nontuberculous mycobacterial infection in children: a 2-year prospective surveillance study in The Netherlands. Clin Infect Dis 39:450-456

2. Lindeboom JA, Kuijper EJ, Bruijnesteijn van Coppenraet ES, Lindeboom R, Prins JM (2007) Surgical excision versus antibiotic treatment for nontuberculous mycobacterial cervicofacial lymphadenitis in children: a multicenter, randomized, controlled trial. Clin Infect Dis 44:1057-1064

3. Lindeboom JA, Prins JM, Bruijnesteijn van Coppenraet ES, Lindeboom R, Kuijper EJ (2005) Cervicofacial lymphadenitis in children caused by Mycobacterium haemophilum. Clin Infect Dis 41:1569-1575

4. Twentsche Courant Tubantia (2003) issue September 11, p 15

5. Reformatorisch Dagblad (2003) issue April 15, p 15

6. Barneveldse Courant (2003) issue August 23, p 3

7. Veluwe (2003) issue July 5, p 3

8. Dagblad de Limburger (2003) issue July 2, p 1

9. Wayne LG, Good RC, Tsang A, Butler R, Dawson D, Groothuis D, Gross W, Hawkins J, Kilburn J, Kubin M (1993) Serovar determination and molecular taxonomic correlation in Mycobacterium avium, Mycobacterium intracellulare, and Mycobacterium scrofulaceum: a cooperative study of the International Working Group on Mycobacterial Taxonomy. Int J Syst Bacteriol 43:482-489

10. Thorel MF, Krichevsky M, Levy-Frebault VV (1990) Numerical taxonomy of mycobactin-dependent mycobacteria, emended description of Mycobacterium avium, and description of Mycobacterium avium subsp. avium subsp. nov., Mycobacterium avium subsp. paratuberculosis subsp. nov., and Mycobacterium avium subsp. silvaticum subsp. nov.. Int J Syst Bacteriol 40:254-260

11. van Soolingen D, Bauer J, Ritacco V, Leao SC, Pavlik I, Vincent V, Rastogi N, Gori A, Bodmer T, Garzelli C, Garcia MJ (1998) IS1245 restriction fragment length polymorphism typing of Mycobacterium avium isolates: proposal for standardization. J Clin Microbiol 36:3051-3054

12. Ritacco V, Kremer K, van der Laan T, Pijnenburg JE, de Haas PE, van Soolingen D (1998) Use of IS901 and IS1245 in RFLP typing of Mycobacterium avium complex: relatedness among serovar reference strains, human and animal isolates. Int $\mathrm{J}$ Tuberc Lung Dis $2: 242-251$

13. Bono M, Jemmi T, Bernasconi C, Burki D, Telenti A, Bodmer T (1995) Genotypic characterization of Mycobacterium avium strains recovered from animals and their comparison to human strains. Appl Environ Microbiol 61:371-373

14. Mijs W, de Haas P, Rossau R, Van der Laan T, Rigouts L, Portaels F, van Soolingen D (2002) Molecular evidence to support a proposal to reserve the designation Mycobacterium avium subsp. avium for bird-type isolates and ' $M$. avium subsp. hominissuis' for the human/porcine type of $M$. avium. Int J Syst Evol Microbiol 52:1505-1518

15. Guerrero C, Bernasconi C, Burki D, Bodmer T, Telenti A (1995) A novel insertion element from Mycobacterium avium, IS1245, is 
a specific target for analysis of strain relatedness. J Clin Microbiol 33:304-307

16. Lindeboom JA, Kuijper EJ, Prins JM, Bruijnesteijn van Coppenraet ES, Lindeboom R (2006) Tuberculin skin testing is useful in the screening for nontuberculous mycobacterial cervicofacial lymphadenitis in children. Clin Infect Dis 43:1547-1551

17. Bruijnesteijn Van Coppenraet ES, Lindeboom JA, Prins JM, Peeters MF, Claas EC, Kuijper EJ (2004) Real-time PCR assay using fine-needle aspirates and tissue biopsy specimens for rapid diagnosis of mycobacterial lymphadenitis in children. J Clin Microbiol 42:2644-2650

18. Bottger EC, Teske A, Kirschner P, Bost S, Chang HR, Beer V, Hirschel B (1992) Disseminated Mycobacterium genavense infection in patients with AIDS. Lancet 340:76-80

19. Komijn RE, de Haas PE, Schneider MM, Eger T, Nieuwenhuijs JH, van den Hoek RJ, Bakker D, van Zijd Erveld FG, van Soolingen D (1999) Prevalence of Mycobacterium avium in slaughter pigs in The Netherlands and comparison of IS1245 restriction fragment length polymorphism patterns of porcine and human isolates. $\mathrm{J}$ Clin Microbiol 37:1254-1259

20. von Reyn CF, Maslow JN, Barber TW, Falkinham JO 3rd, Arbeit RD (1994) Persistent colonisation of potable water as a source of Mycobacterium avium infection in AIDS. Lancet 343:1137-1141

21. Conger NG, O'Connell RJ, Laurel VL, Olivier KN, Graviss EA, Williams-Bouyer N, Zhang Y, Brown-Elliott BA, Wallace RJ Jr (2004) Mycobacterium simae outbreak associated with a hospital water supply. Infect Control Hosp Epidemiol 25:1050-1055

22. Kline S, Cameron S, Streifel A, Yakrus MA, Kairis F, Peacock K, Besser J, Cooksey RC (2004) An outbreak of bacteremias associated with Mycobacterium mucogenicum in a hospital water supply. Infect Control Hosp Epidemiol 25:1042-1049

23. Smole SC, McAleese F, Ngampasutadol J, Von Reyn CF, Arbeit RD (2002) Clinical and epidemiological correlates of genotypes within the Mycobacterium avium complex defined by restriction and sequence analysis of hsp65. J Clin Microbiol 40:3374-3380

24. Matlova L, Dvorska L, Palecek K, Maurenc L, Bartos M, Pavlik I (2004) Impact of sawdust and wood shavings in bedding on pig tuberculous lesions in lymph nodes, and IS1245 RFLP analysis of Mycobacterium avium subsp. hominissuis of serotypes 6 and 8 isolated from pigs and environment. Vet Microbiol 102: $227-236$

25. Thegerstrom J, Marklund BI, Hoffner S, Axelsson-Olsson D, Kauppinen J, Olsen B (2005) Mycobacterium avium with the bird type IS1245 RFLP profile is commonly found in wild and domestic animals, but rarely in humans. Scand J Infect Dis 37:15-20

26. Bauer J, Andersen AB (1999) Stability of insertion sequence IS1245, a marker for differentiation of Mycobacterium avium strains. J Clin Microbiol 37:442-444

27. Johansen TB, Djonne B, Jensen MR, Olsen I (2005) Distribution of IS1311 and IS1245 in Mycobacterium avium subspecies revisited. J Clin Microbiol 43:2500-2502

28. Pavlik I, Svastova P, Bartl J, Dvorska L, Rychlik I (2000) Relationship between IS901 in the Mycobacterium avium complex strains isolated from birds, animals, humans, and the environment and virulence for poultry. Clin Diagn Lab Immunol 7:212-217

29. Dvorska L, Bull TJ, Bartos M, Matlova L, Svastova P, Weston RT, Kintr J, Parmova I, Van Soolingen D, Pavlik I (2003) A standardised restriction fragment length polymorphism (RFLP) method for typing Mycobacterium avium isolates links IS901 with virulence for birds. J Microbiol Methods 55:11-27

30. Portaels F, Realini L, Bauwens L, Hirschel B, Meyers WM, de Meurichy W (1996) Mycobacteriosis caused by Mycobacterium genavense in birds kept in a zoo: 11-year survey. J Clin Microbiol 34(2):319-323 Feb

31. Tell LA, Foley J, Needham ML, Walker RL (2003) Diagnosis of avian mycobacteriosis: comparison of culture, acid-fast stains, and polymerase chain reaction for the identification of Mycobacterium avium in experimentally inoculated Japanese quail (Coturnix coturnix japonica). Avian Dis 47:444-452

32. Shitaye JE, Matlova L, Horvathova A, Moravkova M, DvorskaBartosova L, Treml F, Lamka J, Pavlik I (2008) Mycobacterium avium subsp. avium distribution studied in a naturally infected hen flock and in the environment by culture, serotyping and IS901 RFLP methods. Vet Microbiol 127:155-164

33. Yoder S, Argueta C, Holtzman A, Aronson T, Berlin OG, Tomasek P, Glover N, Froman S, Stelma G Jr (1999) PCR comparison of Mycobacterium avium isolates obtained from patients and foods. Appl Environ Microbiol 65:2650-2653

34. Reed C, von Reyn CF, Chamblee S, Ellerbrock TV, Johnson JW, Marsh BJ, Johnson LS, Trenschel RJ, Horsburgh CR Jr (2006) Environmental risk factors for infection with Mycobacterium avium complex. Am J Epidemiol 164:32-40

35. von Reyn CF, Arbeit RD, Horsburgh CR, Ristola MA, Waddell RD, Tvaroha SM, Samore M, Hirschhorn LR, Lumio J, Lein AD, Grove MR, Tosteson AN (2002) Sources of disseminated Mycobacterium avium infection in AIDS. J Infect 44:166-170 